Portland State University

PDXScholar

5-13-1975

\title{
A Cross Validation of Leary's Level I-M Assessment Method
}

Bruce Leroy Purvine

Portland State University

Follow this and additional works at: https://pdxscholar.library.pdx.edu/open_access_etds

Part of the Psychiatry and Psychology Commons

Let us know how access to this document benefits you.

Recommended Citation

Purvine, Bruce Leroy, "A Cross Validation of Leary's Level I-M Assessment Method" (1975). Dissertations and Theses. Paper 2415.

https://doi.org/10.15760/etd.2411

This Thesis is brought to you for free and open access. It has been accepted for inclusion in Dissertations and Theses by an authorized administrator of PDXScholar. Please contact us if we can make this document more accessible: pdxscholar@pdx.edu. 
AN ABSTRACT OF THE THESIS OF Bruce LeRoy Purvine for the Master of Science in Psychology presented May 13, 1975.

Title: A Cross-Validation of Leary's Level I-M Assessment Method. APPROVED BY MEMIBERS OF THE TTHESIS COMMITMTIME:

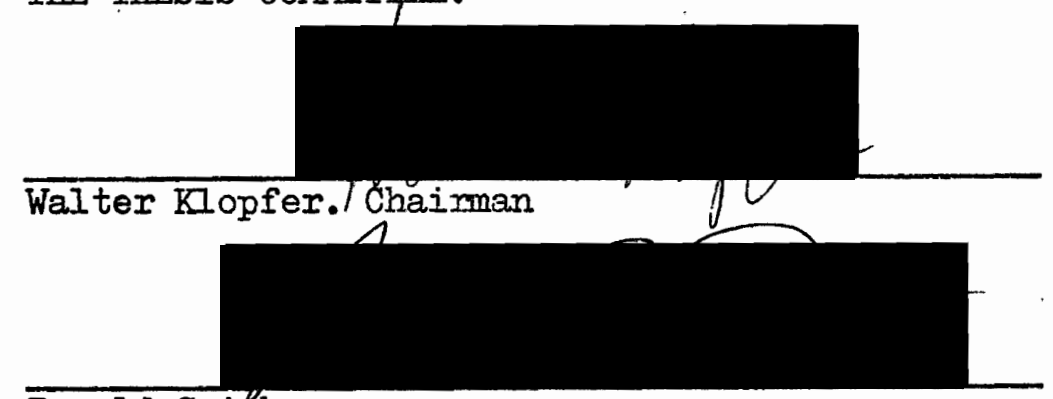

$$
\text { Ronald Smith }
$$

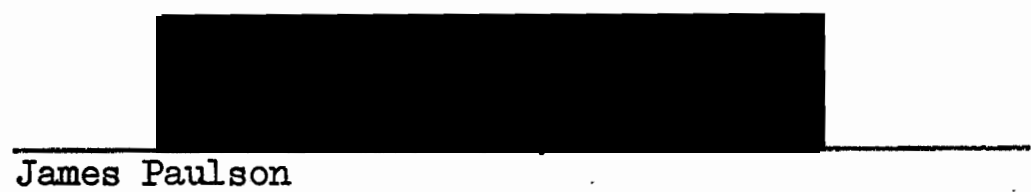

Leary has proposed a method of estimating overt interpersonal behavior from MMPI indices. However, subsequent investigations have only been able to validate a portion of this assessment technique at best.

Thirty adults were individually given the MMPI to obtain estimates of interpersonal vertical (Dom) and horizontal (Lov) scores. Two raters described the subjects using the Interpersonal Checklist (ICI). The mean of these two ratings produced the interpersonal vertical and horizontal scores.

The Pearson Product Moment statistic was applied to the paired sets of vertical and horizontal scores. The results showed no correlation along the vertical or horizontal dimensions. Several possible ex- 
planations for these findings were discussed. It was concluded that Ieary's Level I-M assessment method was not a valid estimate of overt interpersonal behavior. 


\title{
A CROSS VALIDATION OF IEARY'S
}

IEVELL I-M ASSESSMENT METHOD

\author{
by \\ BRTCE LEROY PURVINE
}
A thesis submitted in partial fulfillment of the requirements for the degree of

MASTERR OF SCIENCE

in

PSYCHOLOGY

Portland State University

1975 
TO THE OFFICE OF GRADUATE STUDIES AND RESEARCH:

The members of the Committee approve the thesis of Bruce LeRoy Purvine presented May 13, 1975.
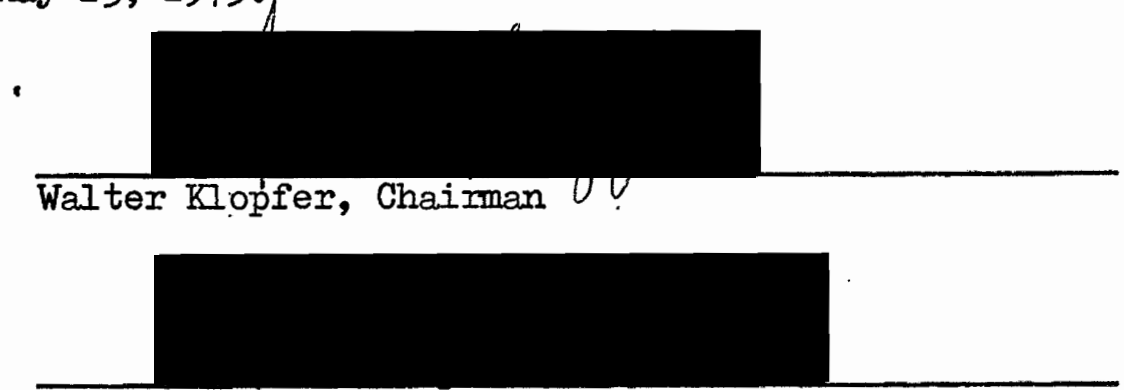

James Paulson
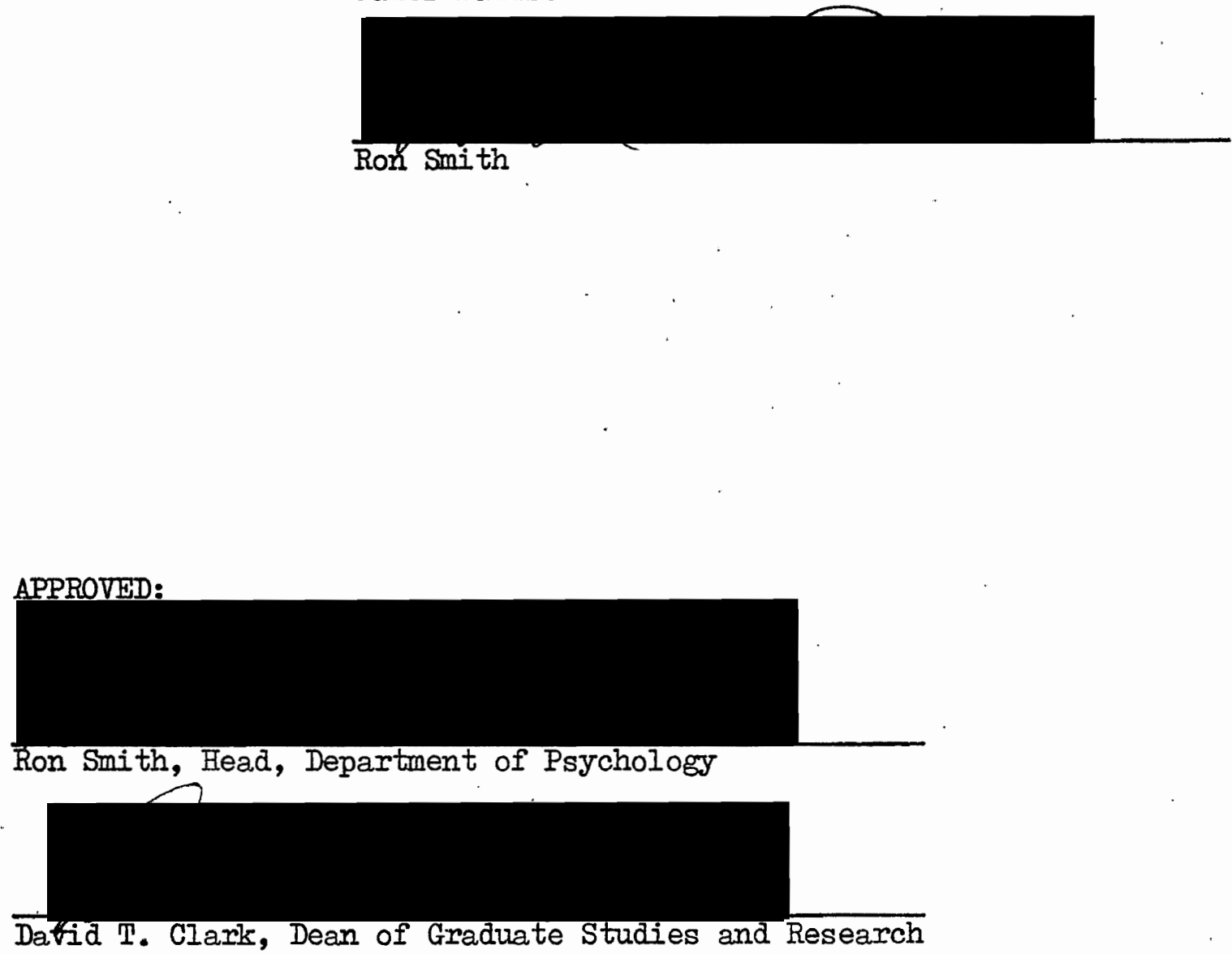

May 21, 1975 
TABLE OF CONTENTS

PAGE

IIST OF FIGURES $\ldots \ldots \ldots \ldots \ldots \ldots \ldots \ldots \ldots \ldots \ldots \ldots \ldots \ldots \ldots \ldots \ldots \ldots \ldots \ldots$ iv

INTRODUCTION $\ldots \ldots \ldots \ldots \ldots \ldots \ldots \ldots \ldots \ldots \ldots \ldots \ldots \ldots \ldots \ldots \ldots \ldots \ldots \ldots \ldots \ldots \ldots \ldots \ldots$

THE INTPERPERSONAL SYSTEM OF PERSONALITY: A REVIEW ........... 3

Interpersonal Levels ............................ 3

Interpersonal Variables ........................... 4

Two Methods of Assessing Behavior at Level I ............ 7

Using the Interpersonal Checklist

Using the Minnesota Multiphasic Personality Inventory

REVIEW OF THE IITERATURE $\ldots \ldots \ldots \ldots \ldots \ldots \ldots \ldots \ldots \ldots \ldots \ldots \ldots \ldots \ldots \ldots \ldots \ldots . \ldots \ldots$

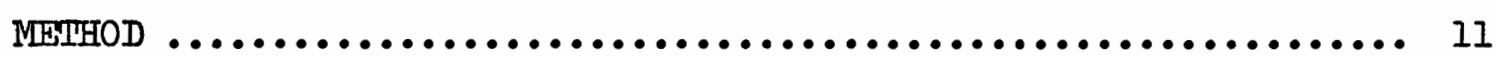

Subjects $\ldots \ldots \ldots \ldots \ldots \ldots \ldots \ldots \ldots \ldots \ldots \ldots \ldots \ldots \ldots \ldots \ldots \ldots \ldots \ldots \ldots \ldots$

Design $\ldots \ldots \ldots \ldots \ldots \ldots \ldots \ldots \ldots \ldots \ldots \ldots \ldots \ldots \ldots \ldots \ldots \ldots \ldots \ldots \ldots$

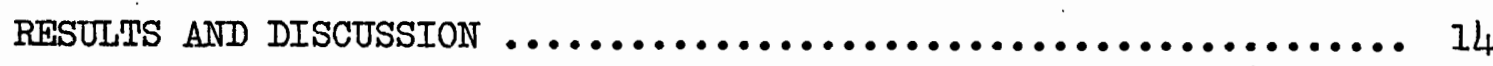

SEHECTED BIBIIOGRAPHY $\ldots \ldots \ldots \ldots \ldots \ldots \ldots \ldots \ldots \ldots \ldots \ldots \ldots \ldots \ldots \ldots \ldots \ldots \ldots$

APPENDIX ...................................... 22 


\section{IIST OF FIGURES}

1. Continuum of Variables For Classifying Interpersonal Behavior With Illustrative Terms .................. 5

2. Standardized Level I-S And Level I-M Summary Point Scores

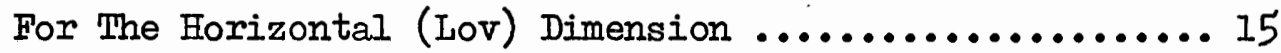

3. Standardized Level I-S And Level I-M Summary Point Scores

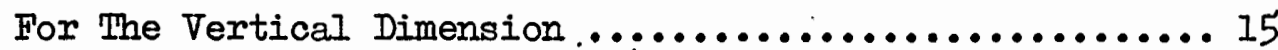

4. Standardized Level I-M Summary Point Scores Arrayed On The Diagnostic Grid .......................... 17

5. Standardized Level I-S Summary Point Scores Arrayed On The Diagnostic Grid 


\section{INTRODUCTION}

Leary (1957) has proposed a method of estimating overt interpersonal behavior from Minnesota Multiphasic Personality Inventory (MNPI) indices. This behavior, labeled Level I behavior or Public Communications, consists of the social stimulus impact of a subject upon others. The events studied are the overt interpersonal activities of the subject. The basic unit involved is the interpersonal effect. Units of Level I behavior are called interpersonal reflexes. This theoretical construct is thought to be an automatic and usually involuntary response to interpersonal situations. The interpersonal reflex is assumed to be expressed by the content of verbal communication and non-verbal cies such as voice inflection and body posture. Individuals may not necessarily be conscious of the favored interpersonal reflexes they employ.

Overt interpersonal behavior is operationally defined accordins to the source of the data or the way the data is produced. Specifically, other persons' descriptions of the subject's interpersonal behavior, as measured along the two dimensions of dominance-submission and love-hate, define Level I overt interpersonal behavior.

In the clinical setting, knowledge of a subject's overt interpersonal behavior may frequently be of use for diagnostic and therapeutic purposes. For example, it would be of interest to note that others consistently describe a subject as strong and dominating, yet interpretation of projective material. showed the subject to be timid, shy and lacking self-confidence. 
As significant others in the life of a subject do not always accompany the subject to the clinical setting, it is difficult to obtain knowledge of a subject's overt interpersonal behavior at the time of intake. In addition, even though the clinician may accurately assess such behavior, the interpersonal reflexes employed by the subject in the clinical setting may differ from those he habitually uses elsewhere. If Ieary's method of estimating overt interpersonal behavior is valid, such information could routinely be secured at the point of intake without much added expense or delay. 
THE INTERPERSONAL SYSTEM OF PERSONALITY: A REVIEW

The interpersonal diagnosis of personality described by Leary (1957) provides a theory of interpersonal behavior and specifies methods to assess that behavior. A description of those facets of the interpersonal diagnosis of personality relevant to this thesis follows.

\section{INTERPERSONAL LEVEIS}

Interpersonal behavior is studied and measured at four levels according to the source of the data or the way the data is produced. The four levels are:

Level I, (Public Communication), consisting of the overt interpersonal behavior of the subject or how the subject presents himself to or is described by others. The basic unit is the interpersonal effect of the subject's behavior upon others. Included here are descriptions by others of the subject.

Level II, (Conscious Descriptions), is concerned with the subject's descriptions of his own interpersonal behavior.

Level III, (Private Symbolization), is comprised of the interpersonal themes produced by the subject in the form of fantasies, projective test stories, dreams and other symbolic expressions.

Level $\mathrm{V}$, (Values), considers the subject's consciously stressed standard or conception of good or proper interpersonal behavior.

There are several different methods of producing data for each level. For example, Level I behavior may be assessed by having signifi- 
cant others describe the subject on the ICL, minute-by-minute ratings of the subject's interpersonal behavior made by trained observers, and MMPI indices have been developed which assert to assess interpersonal behavior.

\section{INTTERPERSONAL VARIABLES}

Data from all levels are related to eight interpersonal variables arranged in a circular continuum around the two axes of DominanceSubmission and Love-Hate. Figure $I$ presents the circular continuum. The eight variables, or octants, are as follows: AP) managerial-autocratic, $B C$ ) competitive-exploitive, $D E$ ) blunt-aggressive, $F G$ ) skepticaldistrustful, HI) modest-self-effacing, JK) docile-dependent, IM) cooperative-overconventional and NO) responsible-overgenerous.

Representation of the interpersonal variables on the circular continuum implies that there is a relationship among the variables, i.e., that adjacent variables are more closely related than nonadjacent variables. Empirical measure support this postulated relationship. LaForge and Suczek (1955) found that the average interoctant correlation decreased as more distant variables were correlated. When the contaminating factor of the over-all likelihood of a "yes" response, regardless of item content, was removed, negative comclations were found whenever variables opposite each other were correlated. It would appear that a rough circular arrangement of the variables can describe their degree of relationship to each other.

An intensity dimension based on endorsement frequency is also represented by the circle. The circle center indicates a mild degree of any variable while the circumference represents an intense degree of any 


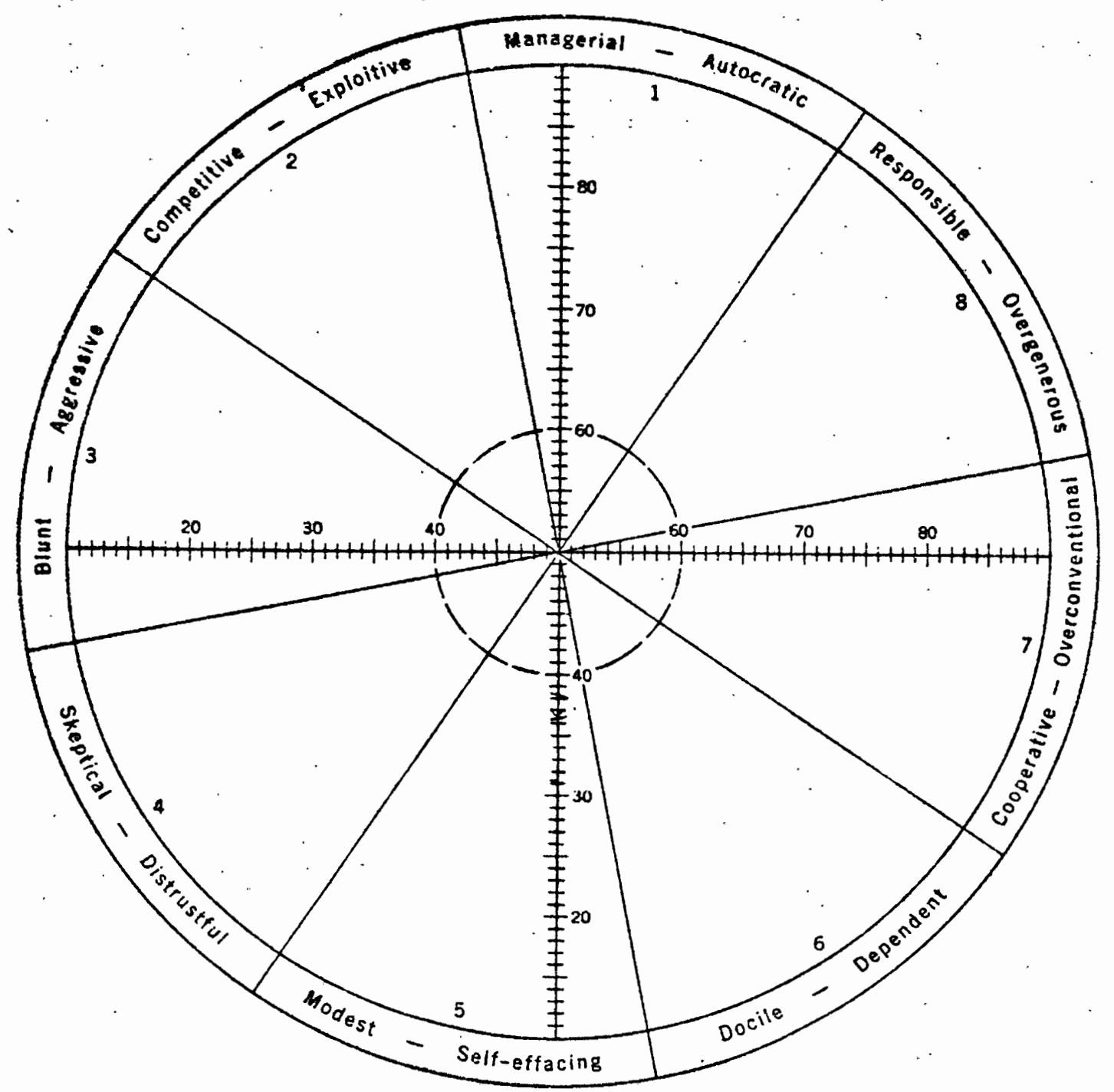

Figure 1. Continuum of variables for classifying interpersonal behavior with illustrative terms. 
variable. For each octant there are sixteen descriptive words or phrases related to that particular interpersonal behavior. Two of these words are rated intensity one and are answered by about ninety per cent of the population. Six words are intensity two items and are answered by about sixty-four per cent. 'Six words are intensity three items and are answered by about thirty-three per cent of the population. Two words are intensity four items and are answered by about ten per cent (IaForge and Suczek 1955). Thus, every intensity classification is equally represented in each of the eight variables.

For research purposes it is convenient to plot a single summary point on the diagnostic circle which represents an individual's position in relation to the mean of a normative group. The diagnostic circle is conceptualized as a two dimensional grid, the center of which is the mean of a normative group. The direction and distance of the summary point from the circle center indicates the type and intensity of interpersonal behavior. It is assumed that the diagnostic circle is a set of eight vectors on a plane. The vector mean is the measure of central tendancy.

A vector in two-dimensional space may be represented numerically by the magnitude of its components in two arbitrarily selected directions. We chose the vertical and horizontal sectors (AP and IM) as reference directions, giving the designations Dom (Dominance) and Lov (Love) respectively to the components of the vector sum in these two directions... The present procedure uses octant scores and .7 was taken as the value of sin 45 degrees; the following simplified formula resulted:

$$
\begin{aligned}
& \text { Dom }=\mathrm{AP}-\mathrm{HI}+.7(\mathrm{NO}+\mathrm{BC}-\mathrm{FG}-\mathrm{JK}) \\
& \text { Lov }=\mathrm{IM}-\mathrm{DE}+.7(\mathrm{NO}-\mathrm{BC}-\mathrm{FG}+\mathrm{JK})
\end{aligned}
$$

where $\mathrm{AP}=$ score octant $\mathrm{AP}$, etc. 1

$I_{\text {Leary, }}$., Multilevel measurement of interpersonal behavior, Berkely, Calif: Psychological Consultation Service, 1956: page 3. 
Scores from the eight interpersonal variable octants are converted into the above two numerical indices and transformed into standard scores. The descriptive interpersonal summary point can then be plotted on the diagnostic grid. Standardization was based on nearly 800 persons, the entire intake population of an outpatient psychiatric clinic over a two year period.

III. TWO METHODS OF ASSESSING BEHAVIOR AT IEVEH I

\section{Using The Interpersonal Checklist}

The Interpersonal Checklist (ICL) (LaForge and Suczek 1955) is a 128-item list of words or phrases used to obtain descriptions of an in- . dividual by others with respect to the interpersonal domain of personality. Rational and empirical approaches were used in its derivation. The rater marks only those words or phrases he thinks descriptive of the subject. Sixteen statements are listed for each octant.

To derive the raw score for any octant, the items checked for that octant are totaled. The raw vertical (Dom) and horizontal (Lov) scores are obtained by plugging the octant scores into the following formulas.

$$
\begin{aligned}
& \text { Dom }=\mathrm{AP}-\mathrm{HI}+.7(\mathrm{NO}+\mathrm{BC}-\mathrm{FG}-\mathrm{JK}) \\
& \text { LOV }=\mathrm{IM}-\mathrm{DE}+.7(\mathrm{NO}-\mathrm{BC}-\mathrm{FG}+\mathrm{JK})
\end{aligned}
$$

These two numerical indices are transformed to standardized scores and the summary point plotted on the diagnostic grid.

Leary (1957) designated this assessment method Level I-S.

\section{Using The Minnesota Multiphasic Personality Inventory}

The MIIPI indices used to estimate overt interpersonal behavior were developed by comparing approximately 200 MNPI profiles with Level I-S 
descriptions (Leary and Coffey 1955a). These studies indicated that the MMPI scales of hypomania (Ma), depression (D), hypochondriasis (Hs), and psychasthenia (Pt) were related to the vertical axis of the diagnostic grid representing Dominant-Submissive behavior. Hysteria (Hy), schizophrenia (Sc), and the $\mathrm{K}$ : and $\mathrm{F}$ validity scales were related to the horizontal axis representing Love-Hate behavior.

In particular, the following relationships were found to correspond to Dominant-Submissive behavior as measured at Level I-S. If $\mathrm{Ma}>\mathrm{D}$ a positive score results indicating interpersonal strength, assertion and confidence emphasized. If $\mathrm{Ma}<\mathrm{D}$ a negative score results indicating a submissive, dependent attitude. If Hs $>$ Pt a positive score results indicating greater concern for physical health than emotional health. If Hs<Pt a negative score results indicating greater emphasis for emotional health than physical concerms.

Along the horizontal axis (Love-Hate) the following relationships were found. If $K>F$ a positive score results indicating attitudes of friendliness, helpfulness and outgoing interpersonal behavior. If $\mathrm{K}<\mathrm{F}$ a negative score results indicating a hostile, self-centered attitude. If Hy> Sc a positive score results indicating bland, naive, superficial agreement. If Hy< Sc a negative score results indicating skepticism and distrust.

These MMPI indices were combined in the following manner to produce vertical (Dom) and horizontal (Lov) interpersonal scores.

$$
\begin{aligned}
& \text { Dom }=(\mathrm{Ma}-\mathrm{D})+(\text { Hs }-\mathrm{Pt}) \\
& \text { Lov }=(\mathrm{K}-\mathrm{F})+(\text { Hy }-\mathrm{Sc})
\end{aligned}
$$

T-scores employing the $K$-correction are to be used for the MMPI 
clinical scales. The MMPI T-scores are then plugged into the above formulas to obtain the raw Dom and Iov interpersonal scores. These two raw scores are converted to standardized scores and plotted on the diagnostic grid. Standardization was based on 787 cases of a psychiatric clinic over a two year period. The circle center was determined by the means of the horizontal and vertical distributions.

Leary (1957) designated this assessment method Level I-M. 


\section{REVIEW OF THE IITERATURE}

Leary and Coffey (1955b) conducted several studies and found a low positive correlation between Level I-S and Level I-M scores for subjects in psychotherapy, ranging from .25 to .67 .

Klopfer (196I) in a cross-validation study found a significant positive correlation of .45 along the horizontal axis (Lov) but not along the vertical (Dom) axis, among college students seen at the counseling center.

Gynther (1962) found no significant relationship with a non-psychiatric sample.

Lafiorge (1963) found a low but a significant correlation of .28 along the vertical axis (Dom) but not along the horizontal axis (Iov), among college students working in a mental health training program.

McDonald (1968) found a reliable positive correlation of .22 along the horizontal axis but not along the vertical axis, among a group of pregnant women living in a dormitory situation.

These contradictory findings indicate that the validity of Leary's Ievel I-M technique is questionable. 
MEITHOD

I. SUBJECTS

The subjects were fifteen men and fifteen women ranging from eighteen years of age to sixty years aged. The mean age for each gender was thirty-one years. Eight women and nine men were in the age range of twenty-three to thirty years. Two males and three females were in their late teens and four subjects for each gender were between the ages of thirty-one and sixty years. All subjects were Caucasians of middle socioeconomic status. Common laborers, skilled laborers and professionals were almost equally represented among the male subjects. The majority of the female subjects were housewives and there were several working women, including a registered nurse and a teacher. Each subject had completed high school and about fifty per cent had completed college. Approximately half the subjects lived in a large metropolitan area, and the remainder resided in small rural towns.

All subjects were acquaintances of the author and a second person who also rated the subjects on the ICL. Each subject was asked to participate in a scientific experiment, the thrust of which was explained. More specifically, they were informed that one test had been devised which showed how persons characteristically respond to others along the dimensions of dominance-submission and love-hate, but that this test required others to rate the subject and that it was often inconvenient to locate others for this purpose. The subjects were then told that 
a second test had been devised which claimed to gather the same information as the first test and that the subject could take this test. It was explained to the subjects that the second test's validity was questionable and that this experiment would use both tests on the same subjects to determine if the results from both tests were the same. An offer was extended to all subjects to let them see the results of their scores and confidentiality was assured. Bvery subject approached agreed to participate.

\section{DESIGN}

Each subject was individually administered the MMPI (booklet form) and answers were recorded on the IBM 805 answer sheets. The answer sheets were scored by hand, using the $\mathrm{K}$-correction to obtain T-scores.

Before scoring the MPI, the author and a second rater, (the wife of the author), independently rated the subjects on the ICL. The mean raw octant scores were used to obtain a concensus for Dom and Lov scores.

Inter-rater agreement was close. Paired Level I-S summary point scores along the horizontal and vertical dimensions were coorelated .93 and .92 respectively. These are both beyond the .01 level of significance. This unusually high agreement between raters is probably due to several factors. In the first place, the raters were a married couple. It is the author's subjective impression that he and the second rater have many common interests and tend to view others in the same manner. Secondly, all subjects were known to both raters for at least three years. During these years of association, most of the subjects related 
to the raters as a maxried couple rather than singularly.

The Pearson Product Moment Correlation was employed to determine the correlation between the paired sets of vertical and horizontal standardized scores.

The null hypotheses tested were that no significant correlations would be found to exist between Level I-S and Level I-M scores along both the vertical (Dom) and the horizontal (Lov) axes.

The alternative hypotheses tested were that positive significant correlations would exist between Level I-S and Level I-M scores along both axes.

$$
\begin{aligned}
& \text { Hо: } r(\text { Dom })=0 \\
& \text { HO: } r \text { (Lov) }=0 \text { - H : } r \text { (Lov) }>0
\end{aligned}
$$

where $r$ is the population correlation. 
RESULTS AND DISCUSSION

A.correlational analysis found an insignificant correlation of -.19 for the horizontal- (Lov) dimension and -.02 for the vertical (Dom) dimension. Figures' 2 and 3 graphically illustrate the lack of significant correlations.

There are several possible factors which may account for the lack of any significant correlations. Leary (1957) thought that the Level I-M method to be a measure of the subject's emotional symptoms and that these psychological symptoms seemed to have interpersonal meaning. Leary wrote that this measure of symptomatic pressure worked best in situations where the subject's emotional symptoms were the crucial factor in determining behavior. A review of the subjects and testing conditions in the previous studies tends to support Leary's hypothesis, if the assumption is made that emotional symptoms influence the behavior of psychotherapeutic patients more so than a "normal" sample. Significant correlations were found where subjects were active participants in psychotherapy. No significant correlations were found in Gynther's (1962) non-psychiatric sample and in the present study, where it may be assumed that intellectual curiousity rather than concerm about emotional symptoms was the motivating factor at the time of testing.

The lack of any significant correlation findings in this study may also be partly due to the principle that traits assessed by different methods possess differences that are important for interpretation (LaForge 1973). It is convenient to define domains of phenomena which 


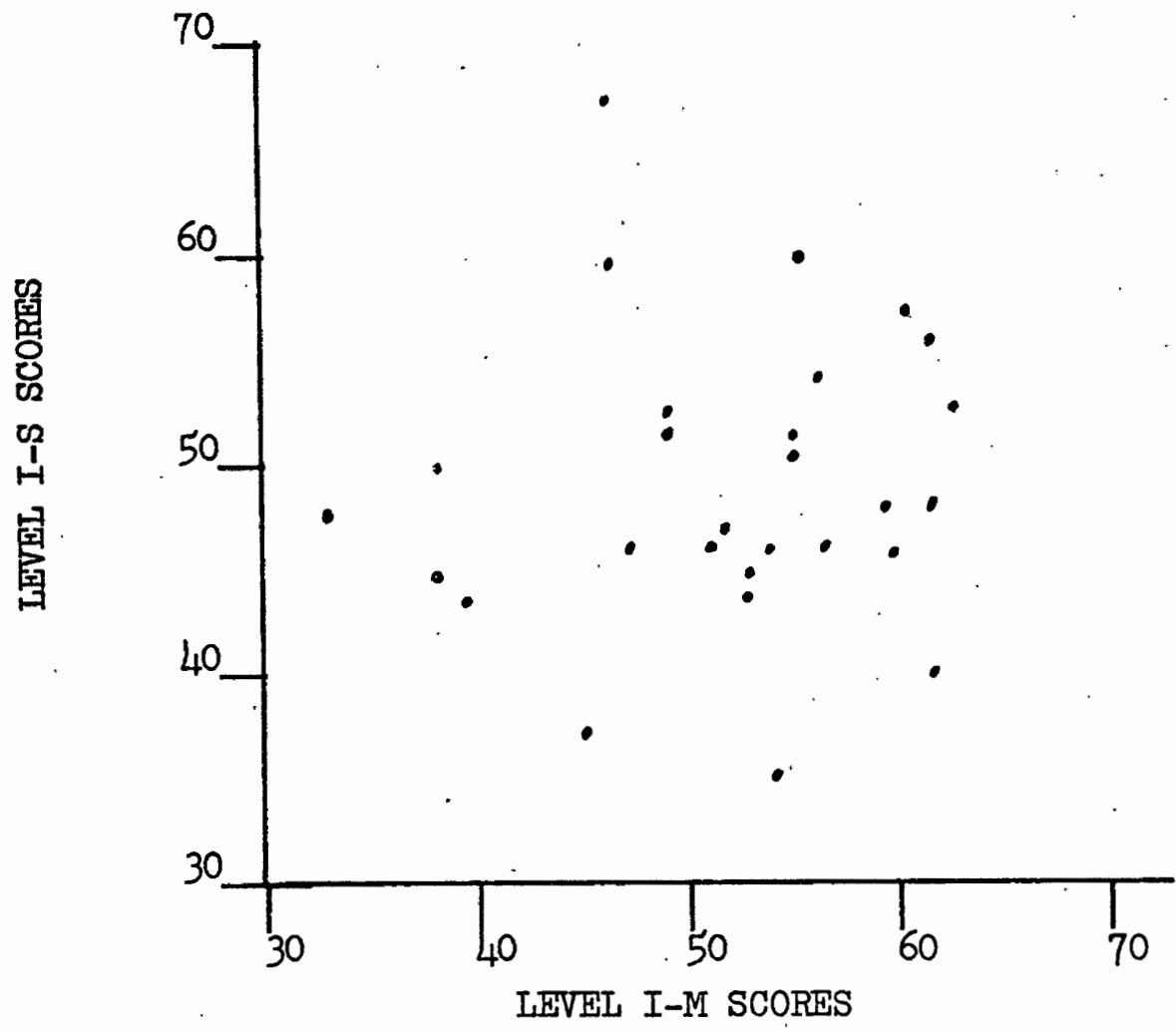

Figure 2: Standardized Level I-S and Level I-M summary point scores for the horizontal (Iov) dimension.

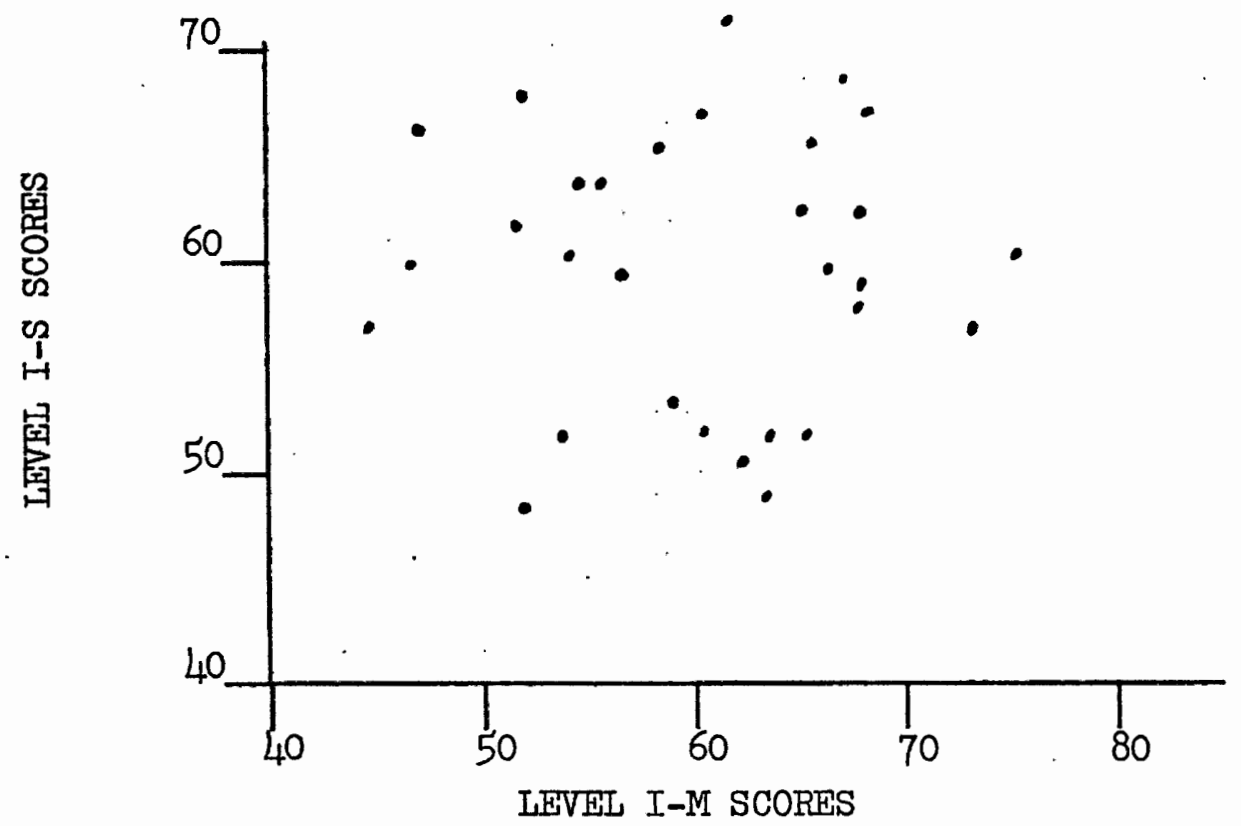

Figure 3. Standardized Level I-S and Level I-M summary point scores for the vertical (Dom) dimension. 
are alike in that they obey the same laws. In the interpersonal schema, the division of personality data into levels, according to the source or manner in which the data was produced, is in recognition of this principle. For example, self-report data may be expected to vary along the lines of social desirability depending upon the relationship between the subject and the investigator. The effects of response sets and situational infiluences are becoming more or less predictable. Knowledge of these factors can be used to qualify objective test results. However, some of the laws giving meaning to self-report data may not apply to data made by others about the subject.

Data obtained by the Level I-S method clearly belongs in the Level I domain as other persons are describing the subject. Data obtained by the Level I-M method is just as clearly self-report data and more appropriately belongs to Level II phenomena. To the extent that laws governing phenomena of one domain do not necessarily apply to phenomena of another domain, different results may occur.

Evidence supports the view that Level I-M data is more closely related to data from Level II than Level I. LaForge (1963) found significant correlations of much greater magnitude along both the horizontal (Lov) and vertical (Dom) axes when he paired Level I-M scores with ICL self-descriptions (Level II) than when he compared Level I-M scores with Level I-S scores, (ICL description by others of the subject).

Figures 4 and 5 show how the Level I-M and Level I-S summary point scores are arrayed on the diagnostic grid.

Along the horizontal axis, the means of the two summary point distributions for this sample are similar to the mean of the standardized 


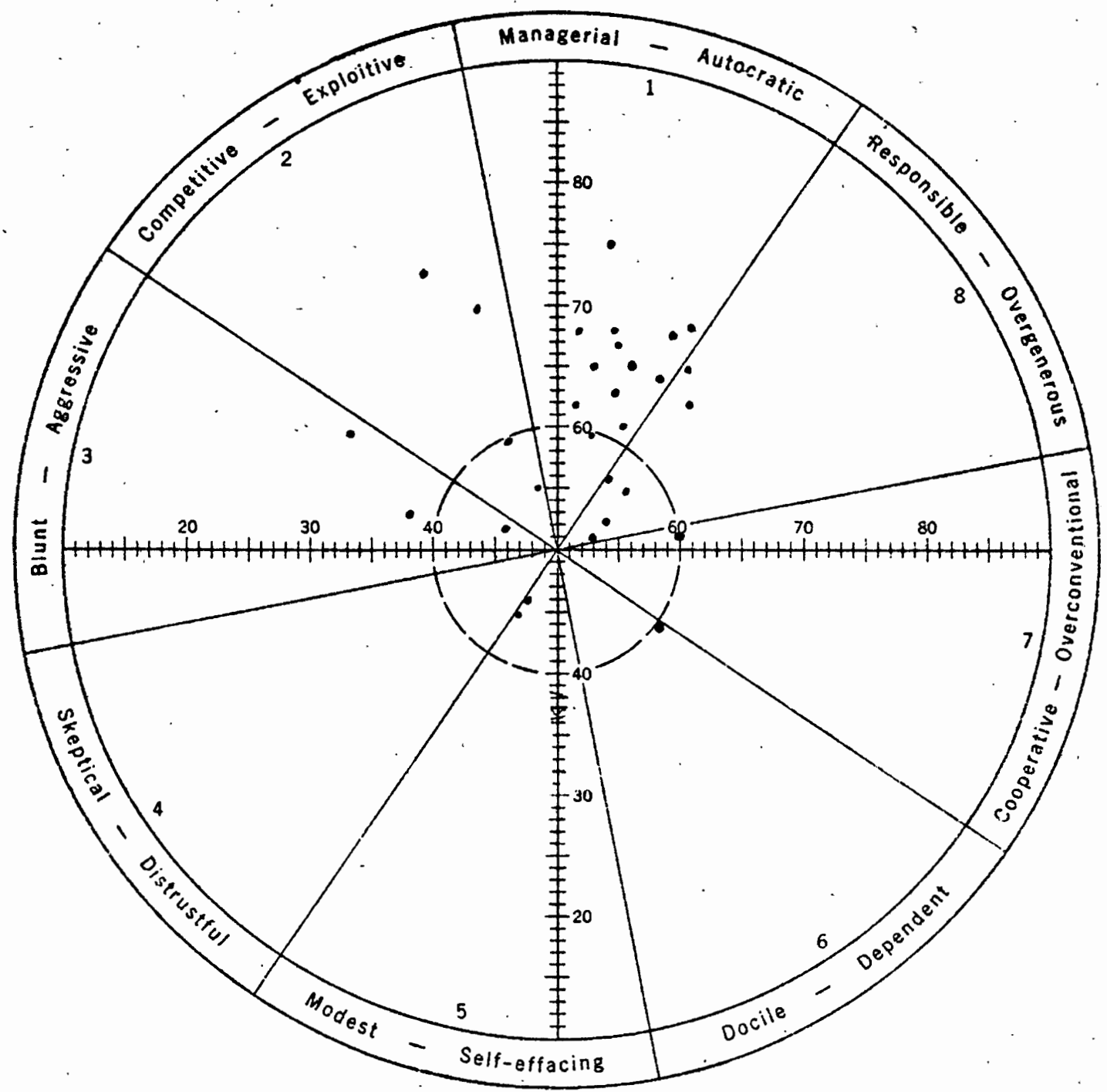

Figure 5. Standardized Ievel I-M summary point scores arrayed on the diagnostic grid. 


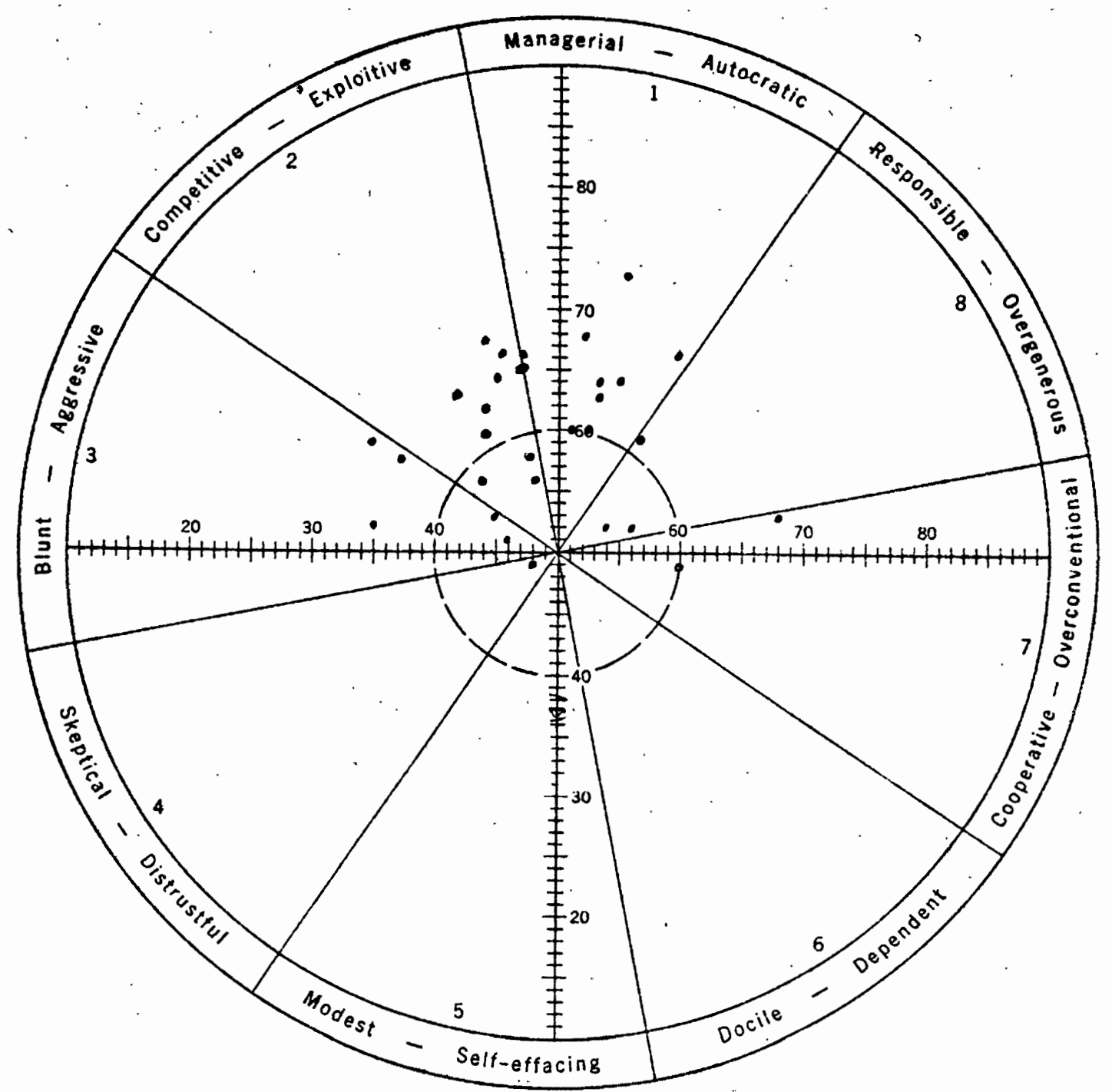

Figure 6. Standardized Level I-S summary point scores arrayed on the diagnostic grid. 
norm of 50 , (Level I-S $=49$, Level I-M $=53$ ).

Along the vertical axis, the means of the two summary point distributions for this sample are both 59. It appears that this sample tends to be more dominating and less submissive than the standardized norms.

Inspection of the scores arrayed on the diagnostic grids indicate that Level I-S and Level I-M scores tended to cluster in the same general area of octants one and two. Autistic or peculiar self-descriptions, or descriptions by others, does not appear to have been the case and therefore this can not account for the lack of correlated findings.

As few scores extended more than halfway toward the circle circumference, the intensity range of scores was also somewhat restricted for this sample. One might speculate that a sample with a greater range of summary point scores, more evenly distributed among all octants, may produce higher correlations. Perhaps the. Level I-M assessment technique is not particularly sensitive to moderate range scores distributed near the dominate portion of the vertical axis. Klopfer (1961) and McDonald (1968) did not obtain significant correlations along the vertical axis. It appears that the Level I-M method is not a valid estimate of overt interpersonal behavior. Although the range of scores along the vertical and horizontal axes was somewhat restricted for this sample population, which would tend to reduce the magnitude of correlation computed by the Pearson Product Moment statistic, this probably does not account for the lack of any significant correlations to any great extent.

Previous attempts to validate the Level I-M technique have been either equally unsuccessful or demonstrated only partial validity. 
Therefore, another more general factor seems to be influencing the obtained results. It is the conclusion of this author that the Level I-M method, (self-report data), and the Level I-S method, (descriptions

- about a subject made by others), belong to different domains of phenomena. To the extent that the laws governing the phenomena of these two domains are not identical, different results will occur. 
SELECTED BIBLIOGRAPHY

Gynther, M.D. Degree of agreement among three "Interpersonal Systems" : measures. Journal of Consulting Psychology, 1962, 26, 107.

Klopfer, W.G. A Cross-validation of Leary's "Public Communication Level". Joumal of Clinical Psychology, 1961, 17, 321-322.

LaForge, R. Interpersonal Domains of Interpersonal Levels? A Validation Study of Leary's "MMPI Level I Indicies". Paper read at the Western Psychological Association Meetings in Santa Monica, Calif., on April 19, 1963.

LaForge, R. Using the ICL, Unpublished manuscript, 1973.

IaForge, R. and Suczek, R.F. The Interpersonal Dimension of Personality: III. An Interpersonal Checklist. Journal of Personality, 1955, 24, 94-112.

Leary, T. Multilevel Measurement of Interpersonal Behavior. Berkeley, Calif: Psychological Consultation Service, 1956.

Leary, T. Interpersonal Diagnosis of Personality. New York: Ronald Press, 1957 .

Leary, T. and Coffey, H.S. Interpersonal Diagnosis: Some Problems of Methodology and Validation. Jourmal of Abnormal and Social Psychology, 1955, 50, 110-124.(a)

Leary, T. and Coffey H.S. The Prediction of Interpersonal Behavior in Group Psychotherapy. Psychodrama and Group Psychotherapy. Monograph, 1955, 28.(b)

McDonald, R.I. Leary's Overt Interpersonal Behavior: A Validation Attempt. Journal of Social Psychology, 1968, 74, 259-264. 


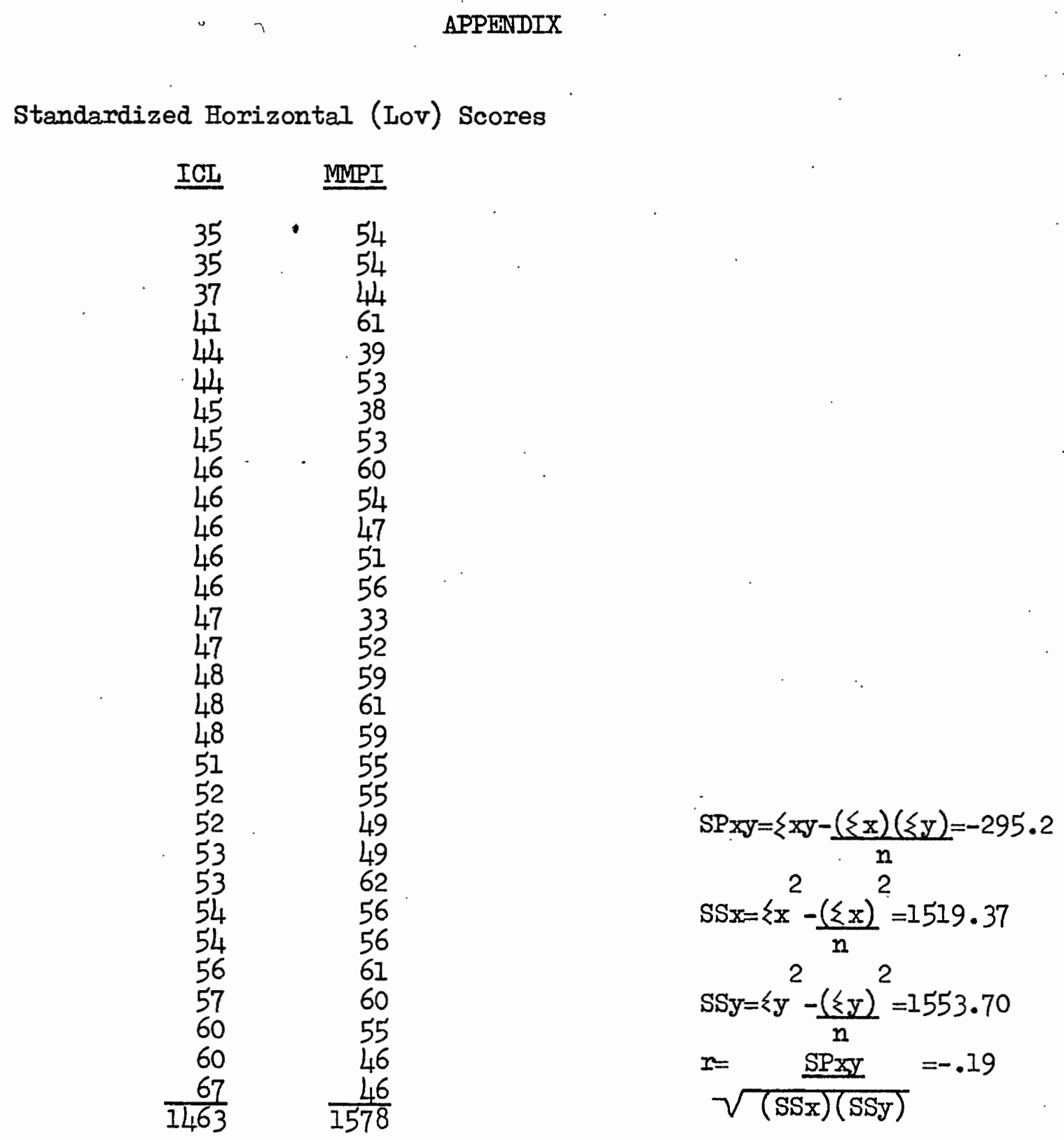


Standardized Vertical (Dom) Scores

\begin{tabular}{cc} 
ICL & MMPI \\
\hline 48 & \\
49 & 51 \\
$5 I$ & 63 \\
52 & 62 \\
52 & 53 \\
52 & 63 \\
52 & 60 \\
53 & 65 \\
56 & 59 \\
56 & 72 \\
57 & 44 \\
58 & 68 \\
59 & 68 \\
59 & 56 \\
60 & 67 \\
60 & 53 \\
60 & 75 \\
62 & 46 \\
63 & 51 \\
63 & 64 \\
64 & 68 \\
64 & 55 \\
65 & 54 \\
65 & 58 \\
66 & 65 \\
66 & 45 \\
66 & 59 \\
67 & 68 \\
68 & 51 \\
71 & 67 \\
\hline 1784 & 61 \\
& 1791 \\
&
\end{tabular}

$$
\begin{aligned}
& \mathrm{SPxy}=\left\langle x y-\frac{(\langle x)(\langle y)}{n}=-30.80\right. \\
& 2 \quad 2 \\
& S S x=\left\{x-\frac{\left(\sum x\right)}{n}=1102.13\right. \\
& S S y=\left\langle y^{2}-\frac{(\xi y)^{2}}{n}=2410.30\right. \\
& r=\quad \text { SPXy }=-.02 \\
& \sqrt{(\mathrm{sSx})(\mathrm{sSy})}
\end{aligned}
$$

